\title{
Relation of Earliness to Some Plant Characters in the Tomato ${ }^{1}$
}

\author{
Agripino Pérez López
}

\section{INTRODUCTION}

Very little has been learned about the actual mechanism of the inheritance of earliness in the tomato. One reason for this is the lack of a good criterion of earliness. As stated by Rick and Butler $(1)^{3}$ the main criteria of earliness have been comparison with the standard variety, the onset of the various growth phases being scored as days earlier or later than the standard, or the number of days necessary to complete a certain phase of growth, such as seeding to the first ripe fruit. This study was performed in the effort to add some information to our knowledge about earliness in the tomato.

\section{MATERIALS AND METHODS}

This experiment was performed at the Isabela Agricultural Experiment Substation, on a Coto sandy clay soil during the summer of 1959. Four tomato varieties (namely: Earliana, first early; Valiant, second early; Queens, midseason; and Rutgers, late) were included in a randomized complete-block design for this study. Each variety was replicated five times, with seven plants per replication. Enough seed of each variety were sowed on flats and the mcst uniform plants were selected at the time of transplanting. The plants were set to form a $5 \times 3$-foot lattice and were fertilized with a 9-10-5 commercial fertilizer at the rate of 1,200 pounds per acre.

Information was recorded as follows: Rate of leaf production at weekly intervals during 6 weeks, node number at which the first consecutive four flower clusters appeared on the main stem, and percentage of the first four flowering branches originating four leaves below or above the position of the first flower cluster on the main stem. The letters MA, MB, MC, and MD are used in this study to denote the first, second, third, and fourth flower clusters, respectively, originating on the main stem.

1 Contribution from the Isabela Agricultural Experiment Substation.

2 Research Assistant in Horticulture, Agricultural Experiment Station, University of Puerto Rico, Río Piedras, P. R. The author wishes to express his sincere gratitude to Dr. O. Shifriss, Associate Professor of Vegetable Breeding, New Jersey Agricultural Experiment Station, New Brunswick, N. J., for the suggestion of this problem, and to other members of the Isabela Agricultural Experiment Substation for the assistance and cooperation during the course of this study .

${ }^{3}$ Italic numbers in parentheses refer to Literature Cited, p. 250. 
The first and the last plants of each replication were used to obtain the fresh and dry weight of five mature leaves, and of the entire plants. The stem diameter two leaves below the first inflorescence was measured when the plants were ready for the first fruit harvest. The yield was recorded in terms of number and weight of ripe fruits.

\section{RESULTS AND DISCUSSION}

\section{DAYS FROM PLANTING DATE TO FIRST FRUIT HARVEST}

The mean number of days from planting date to the harvest of the first ripe fruits on the four tomato varieties was: $79.00,73.40,72.20$, and 71.00 for Rutgers, Queens, Valiant, and Earliana, respectively. There was no significant difference between Queens and Valiant or between Valiant and Earliana; however, there was a significant difference between Earliana and Queens in the nunber of days from planting to the first fruit harvest. The difference between Rutgers and the other three varieties was highly significant. (See figure 1.) The standard error and least differences required for significance between mean number of days required for the harvest of the first ripe fruit are presented in the following tabulation:

Ilem

Least significant difference between highest and lowest means

Least significant difference between highest and 2nd lowest

Least significant difference between 2 adjacents

Standard error 0.52 with 12 d.f.

$\begin{array}{cc}\text { 5-percent level } & \text { J-percent level } \\ 2.18 & 2.86 \\ 1.96 & 2.62 \\ 1.60 & 2.25\end{array}$

-percent level

\section{RATE OF LEAF PRODUCTION}

\section{Varietal Leaf Production}

The rate of leaf production for the four tomato varieties is presented in table 1 and figure 2. Earliana, the first early variety, during any week period produced significantly more leaves than any of the other varieties studied. The total mean number of leaves produced during a 6 -week period was: $7.06,4.44,4.23$, and 3.47 for Earliana, Rutgers, Valiant, and Queens, respectively. The standard error and least differences required for significance between the mean number of leaves per variety are shown in the following tabulation:

Item

Least significant difference between highest and lowest means

Least significant difference between highest and 2nd lowest

Least significant difference between 2 adjacents

Standard error 0.68 with 92 d.f.

$\begin{array}{cc}\text { 5-percent lerel } & \text { 1-percent lecel } \\ 2.53 & 3.09 \\ 2.30 & 2.88 \\ 1.92 & 2.54\end{array}$


The number of leaves of Earliana was highly significant over those of Rutgers and Queens. The difference between Earliana and Valiant was significant only at the 5-percent level. Comparisons among Valiant, Queens,

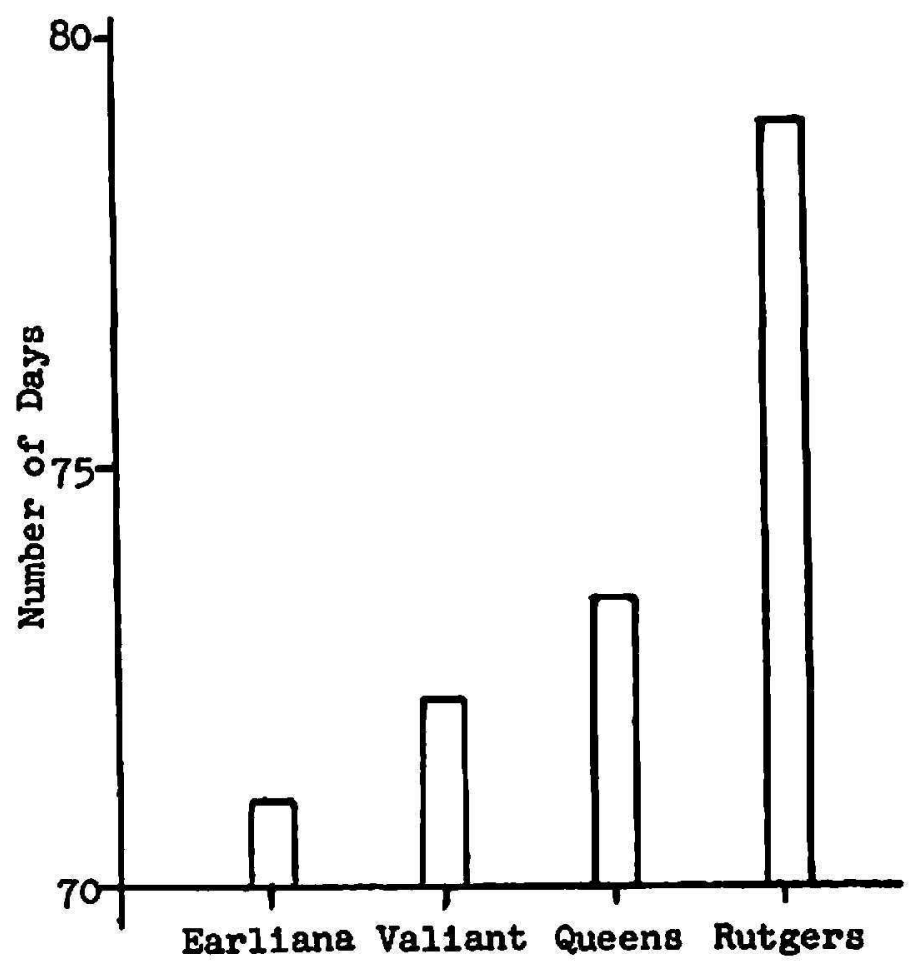

Fig. 1.-Mean total number of days required from sowing date to the harvest of the first mature fruits for 4 tomato varieties.

TABLE 1.-Mean number of leaves produced from the 2-leaf seedling stage, at weekly intervals during 6 weeks on the 4 tomato varieties studied

\begin{tabular}{c|r|r|r|r|r}
\hline \multirow{2}{*}{ Week } & \multicolumn{3}{|c|}{ Leaves produced by variety indicated } & \multirow{2}{*}{ Means } \\
\cline { 2 - 5 } & Earliana & Valiant & Queens & Rutgers & \\
\hline 1 & 5.18 & 3.96 & 3.57 & 3.71 & 4.11 \\
2 & 3.40 & 2.60 & 2.43 & 2.54 & 2.74 \\
3 & 4.09 & 2.66 & 2.49 & 2.83 & 3.02 \\
4 & 5.06 & 2.14 & 1.99 & 2.06 & 2.81 \\
5 & 7.25 & 3.67 & 2.94 & 4.00 & 4.47 \\
6 & 17.40 & 10.35 & 7.37 & 11.49 & 11.65 \\
\cline { 2 - 4 } Means & 7.06 & 4.23 & 3.47 & 4.44 & 4.80 \\
\hline \hline
\end{tabular}

and Rutgers did not show any significant differences. It appears that an early variety has a high physiological activity which enables it to produce a great number of leaves within a certain period of time. These results tend to indicate that the rate of leaf production can be used as a criterion to measure earliness in this particular variety. 


\section{Weekly Leaf Production}

Regardless of the variety, the total means for the weekly leaf productions (table 1) were: $11.65,4.47,4.11,3.02,2.81$, and 2.74 for the sixth, fifth, first, third, fourth, and second week, respectively. During the sixth week highly significantly more leaves were produced than in any other week.

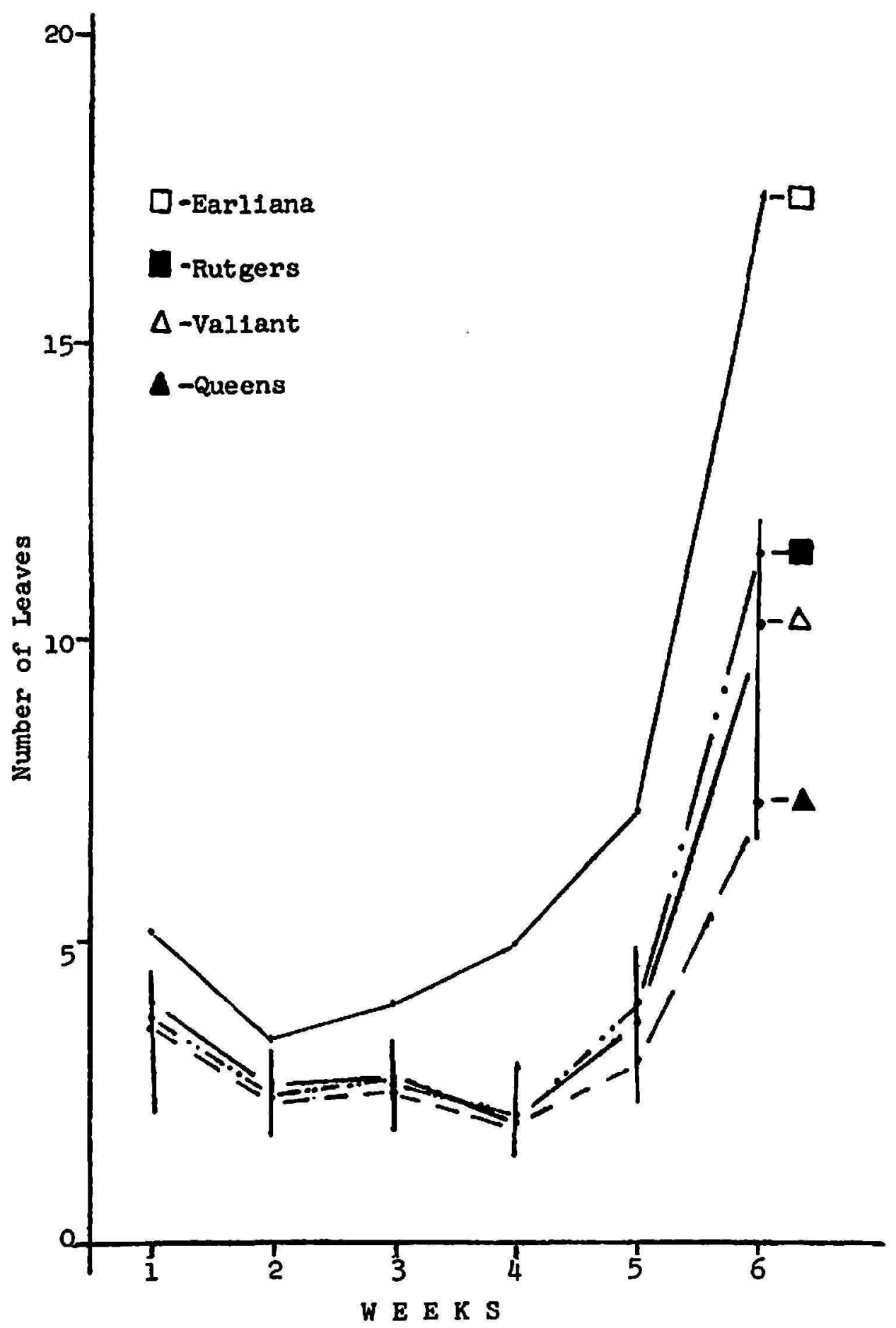

Fig. 2.-Mean total number of leaves per tomato variety at 1-week intervals. Means not enclosed by vertical lines differ significantly at the 1-percent level; means enclosed by vertical lines do not differ significantly. 
Comparisons among the other 5-week periods showed no significant differences. The standard error and least differences required for significance between mean weekly productions of leaves, in table 1, are presented in the following tabulation:

Item

Least significant difference between highest and lowest means

Least significant difference between highest and 2nd lowest

Least significant difference between highest and 3d lowest

Least significant difference between highest and 4th lowest

Least significant difference between 2 adjacents Standard error 0.68 with 92 d.f.

$\begin{array}{cc}5 \text {-percent lesel } & \text { I-percent level } \\ 2.81 & 3.35 \\ 2.69 & 3.24 \\ 2.53 & 3.00 \\ 2.30 & 2.88 \\ 1.92 & 2.54\end{array}$

TABLE 2.-Mean squares for the mean total number of leaves produced during 1-week periods by the 4 tomato varieties studied

\begin{tabular}{l|c|c}
\hline Source of variation & Degrees of freedom & Mean squares' \\
\cline { 2 - 3 } Varieties & 3 & 73.58 \\
Weeks & 5 & 235.61 \\
Weeks x varieties & 15 & 10.14 \\
Error & 92 & 2.29 \\
\hline
\end{tabular}

${ }^{1} F$ value significant at the 1-percent level.

'The large number of leaves produced during the sixth week could be due to the fact that, at that time, all the varieties were ramified and many leaves were produced in each ramification.

The highly significant interaction between weeks and varieties indicates that the rate of increase in the weekly leaf production is not equal for the different tomato varieties. The analysis of variance for this interaction is presented in table 2.

\section{NODE NUMBER ON THE MAIN STEM AT WHICH THE FIRST FOUR FLOWER CLUSTERS APPEARED}

\section{Mean Tolal Node Number when MA Appeared on Main Stem}

The node number at which the first flower cluster (MA) appeared on the main stem (table 3 and figure 3 ) was 13.54, for Rutgers, 12.14 for Queens, 11.65 for Valiant, and $\mathbf{1 0 . 0 5}$ for Earliana. In Earliana a highly significantly smaller number of nodes from the cotyledonal leaves to the appearance of the first inflorescence was produced as compared with Rutgers and Queens. This tends to indicate that in an early tomato variety a small 
TABLE 3.-Mean number of leaves up to the appearance of the first, second, third, and fourth inflorescences on the main stem of the 4 tomato varieties studied

\begin{tabular}{l|r|r|r|r}
\hline \multirow{2}{*}{ Inflorescence } & \multicolumn{3}{|c}{ Leaves appearing on variety indicated } \\
\cline { 2 - 5 } & Earliana & Valiant & Queens & Rutgers \\
\hline First & 10.05 & 11.65 & 12.14 & 13.54 \\
Second & 6.41 & 3.33 & 3.05 & 3.45 \\
Third & 3.47 & 2.82 & 2.94 & 3.19 \\
Fourth & 3.06 & 3.00 & 2.94 & 2.86 \\
\hline \hline
\end{tabular}

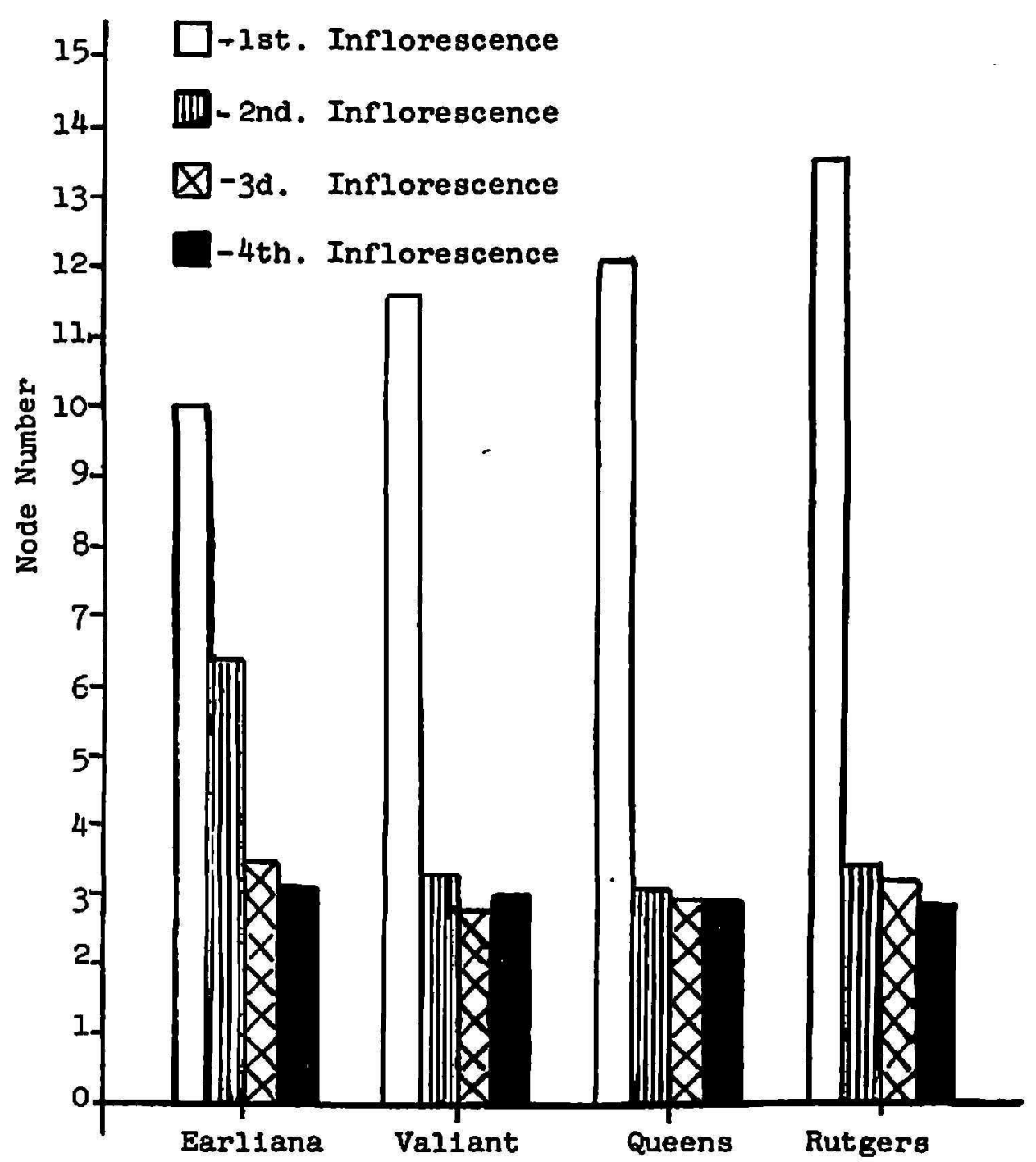

FIg. 3.-Position at which first 4 flower clusters appeared on the main stems of 4 tomato varieties.

number of nodes may be found up to the appearance of the first inflorescence. The difference between Queens and Valiant was nonsignificant. The standard error and least differences required for significance between mean numbers of nodes to $\mathrm{MA}$ are presented on the following tabulation: 
Item

Least significant difference between highest and lowest means

Least significant difference between highest and 2nd lowest

Least significant difference between 2 adjacents

Standard error 0.31 with 12 d.f. 5-percent lezel

1.17

.95
I-percent level

1.71

1.56

1.34

\section{Mean Total Nodes after $M A$ when $M B$ Appeared on Main Stem}

Table 3 and figure 3 show that Earliana took 6.41 nodes after MA to produce the second flower cluster. The other three varieties took highly significantly fewer nodes after MA to produce the second flower cluster. The differences among Rutgers, Queens, and Valiant were not significant. The large number of nodes between $\mathrm{MA}$ and $\mathrm{MB}$ in Earliana suggests that this variety needs an excessive vegetative growth to make up for the nutrient consumption while producing an early flower cluster at a height of 10 nodes above the cotyledonal leaves, at least as compared with the other varieties which produced a larger number of nodes. The total mean number of nodes after MA that MB appeared was 6.41, 3.45, 3.33, and 3.05 for Earliana, Rutgers, Valiant, and Queens, respectively. The standard error and least differences required for significance between mean total numbers of nodes after MA that MB appeared are presented in the following tabulation:

Ilem

Least significant difference between highest and lowest means

Least significant difference between highest and 2nd lowest

Least significant difference between 2 adjacents Standard error 0.18 with 12 d.f.
S-percent level

0.76

.68

.55 1-percent leve

0.99

.91

.78

\section{Mean Total Nodes after MB when MC Appeared on Main Stem}

The mean total number of nodes after MB that MC appeared on the main stem 3.47, 3.19, 2.94, and 2.82 for Earliana, Rutgers, Queens, and Valiant, respectively. Table 3 and figure 3 show that Earliana produced significantly more nodes to produce its third flower cluster than any of the other three varieties. The difference of Earliana over Valiant and Queens was significant at the 1-percent level, whereas the difference of Earliana and Rutgers was significant at the 5-percent level. Differences of Rutgers over Queens and Valiant were significant at the 5-percent level only. The difference between Valiant and Queens was not significant. The standard 
error and least differences required for significance between the mean numbers of nodes after MB that MC appeared on the main stem are presented on the following tabulation:

IIem

Least significant difference between highest and lowest means

Least significant difference between highest and 2nd lowest

Least significant difference between 2 adjacents

Standard error 0.077 with 12 d.f.

$\begin{array}{cc}\text { 5-percent level } & \text { I-percenl level } \\ 0.32 & 0.42 \\ .29 & .39 \\ .24 & .33\end{array}$

\section{Mean Number of Nodes after MC when MD Appeared on Main Stem}

Table 3 and figure 3 show the mean number of nodes after MC that MD appeared on the main stem. The differences between varieties were not significant. This may indicate that, on some occasions the early as well as the late varieties may produce their successive flower clusters after equal numbers of nodes. The mean total number of nodes after MC that MD appeared on the main stem was 3.06, 3.00, 2.94, and 2.86 for Earliana, Valiant, Queens, and Rutgers, respectively.

These results suggest that, in Earliana, the fact of producing the first flower cluster (MA) after a short number of nodes from the cotyledonal leaves could cause an unbalanced condition in the plant, forcing it to produce a larger number of nodes between the first and second, and between the second and third flower clusters as compared with the other varieties. The results for the number of nodes between inflorescences are partly in accordance with Yeager (2) who stated that most varieties of tomato have three internodes between inflorescences.

\section{MEAN PERCENTAge OF FIRST FOUR FLOWERING BRANCHES ORIGINATING FOUR LEAVES BELOW OR ABOVE POSITION OF FIRST INFLORESCENCE ON MAIN STEM}

The main percentage of the first four flowering lateral branches originating four leaves below or above position of the first flower cluster on the main stem was $\mathbf{7 5 . 8 0}$ for Earliana, $\mathbf{5 3 . 6 0}$ for Valiant, $\mathbf{5 2 . 0 0}$ for Queens, and 45.00 for Rutgers (see fig. 4). This result demonstrated that, in Earliana, most of the first four flowering lateral branches appeared closer to or above the first flower cluster than in the other varieties studied. This difference was significant at the 5-percent level, whereas the differences among Valiant, Queens, and Rutgers were not significant. The standard error and least differences required for significance between mean percentages of 
lateral branches originating four leaves below or above position of MA are presented in the following tabulation:

Ilem

Least significant difference between highest and lowest means

Least significant difference between highest and 2nd lowest

Least significant difference between 2 adjacents Standard error 6.20 with 12 d.f.

$\begin{array}{cc}\text { 5-percent level } & \text { I-percent level } \\ 26.04 & 34.10 \\ 23.37 & 31.25\end{array}$

$19.10 \quad 26.78$

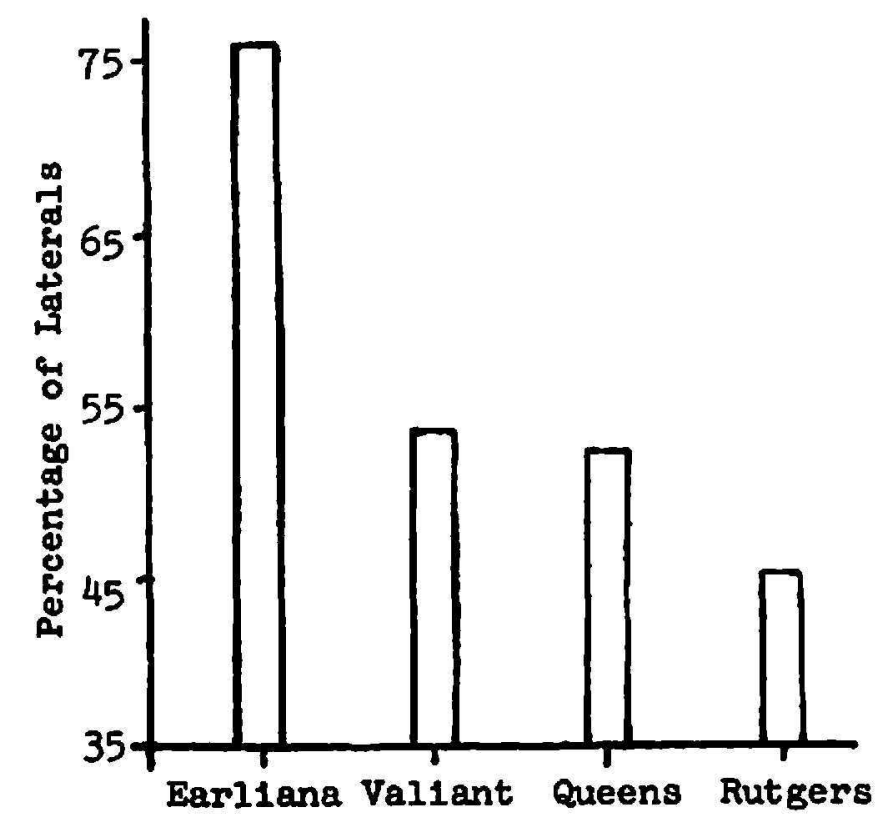

Fra. 4.-Mean percentage of lateral branches originating 4 leaves below or above position of the first inflorescence on the main stems of 4 tomato varieties.

\section{FRESH AND DRY WEIGHT OF FIVE MATURE LEAVES PER PLANT AND FOR WHOLE PLANTS}

\section{Fresh Weight of Leaves}

In table 4 and figure 5 are shown the results on fresh weight for the mature leaves. This weight, in grams, was $36.43,26.40,23.53$, and 19.19 for Rutgers, Queens, Valiant, and Earliana, respectively. These results show that the Rutgers leaves weighed highly significantly more than those of any of the other three varieties. Queens' leaves weighed significantly more than Earliana's. The difference between Queens and Valiant and between Valiant and Earliana were statistically nonsignificant. The standard error and least differences required for significance between the mean fresh weights of the mature leaves are presented in the following tabulation: 
Ilem

Least significant difference between highest and lowest means

Least significant difference between highest and 2nd lowest

Least significant difference between 2 adjacents

Standard error 1.55 with 12 d.f. 5-percent lesel t-percent level
6.51
8.52

5.84

7.81

4.77

6.70

It appears that the high rate of leaf production may account for the small size of leaves in Earliana. This may be possible if we assume that

TABLE 4.-Mean fresh and dry weights, in grams, of entire plants and of 5 mature leaves of tomalo in the 4 tomato varielies sludied

\begin{tabular}{l|r|r|r|r}
\hline \multirow{2}{*}{ Part of plant and basis } & \multicolumn{3}{|c}{ Weights for varieties indicated } \\
\cline { 2 - 3 } & Earliana & \multicolumn{1}{|c|}{ Valiant } & \multicolumn{1}{|c}{ Queens } & \multicolumn{1}{|c}{ Rutgers } \\
\hline Tresh weight & & & & \\
$\quad$ 5 leaves & 15.19 & 23.53 & 26.40 & 36.43 \\
$\quad$ Whole plant & 519.62 & 446.55 & 347.58 & 685.18 \\
& & & & \\
Dry weight & 8.79 & 9.37 & 9.94 & 11.01 \\
$\quad$ 5 leaves & 107.96 & 89.61 & 75.30 & 127.31 \\
$\quad$ Whole plant & & & & \\
\hline \hline
\end{tabular}

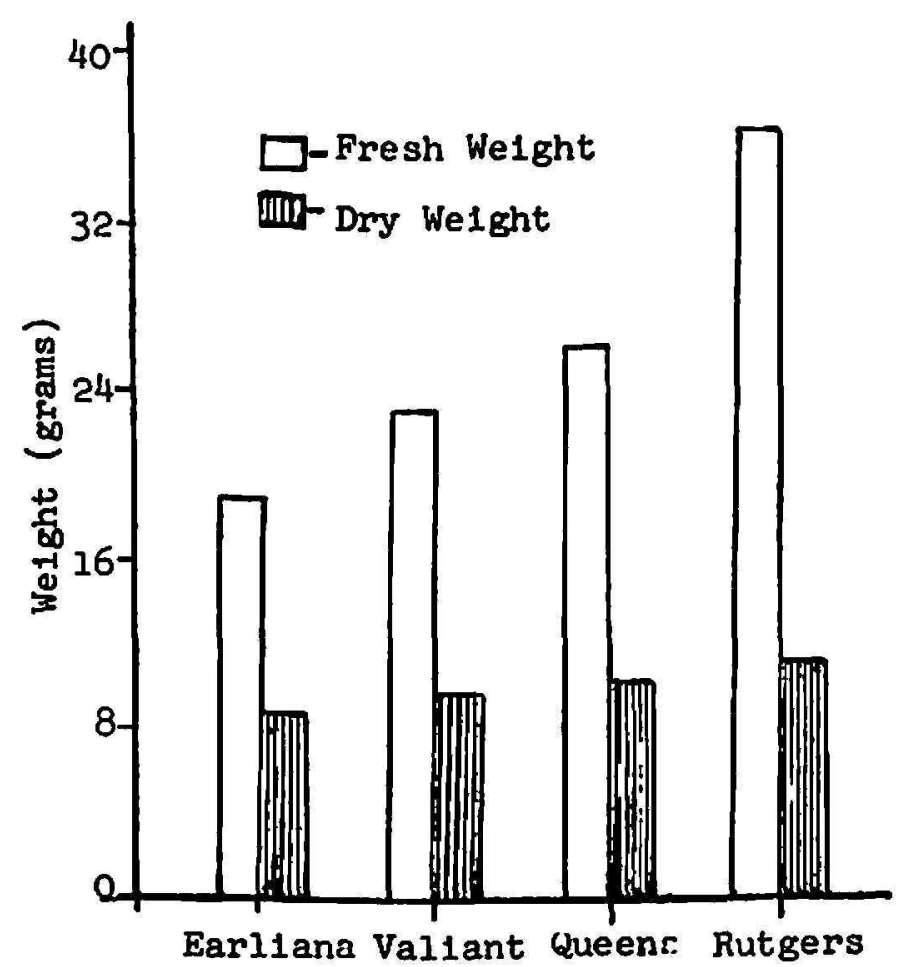

Fig. 5.-Mean total fresh and dry weights of 5 mature leaves formed by 4 tomato varieties. 
the nutrients of the plant are used in formation of more leaves instead of in increasing leaf size.

\section{Dry Weight of Leaves}

In table 4 and figure 5 are also shown the results for the dry weight of leaves. As can be seen in table 4, the fresh and dry weight of leaves rank in the same order of statistical significance. The mean total leaf dry weight (table 4) was 11.01, 9.94, 9.37, and 8.79 for Rutgers, Queens, Valiant, and Earliana, respectively. The standard error and least differences required for significance between mean leaf dry weights are pesented in teh following tabulation:

Item

Least significant difference between highest and lowest means

Least significant difference between highest and 2nd lowest

Least significant difference between 2 adjacents

Standard error 0.22 with 12 d.f.

$\begin{array}{cc}\text { 5-percent level } & \text { I-percent level } \\ 0.94 & 1.23 \\ .84 & 1.13 \\ .69 & .97\end{array}$

\section{Fresh Weight of Whole Plants}

In table 4 is shown the mean fresh weight for whole plants. These means are: $685.18,519.62,446.65$, and 347.58 for Rutgers, Earliana, Valiant and Queens, respectively. These results demonstrated that the Rutgers plants weighed significantly more than those of Valiant, and highly significantly more than those of Queens. The difference between Rutgers and Earliana was nonsignificant. The reason for this result could be that, at the time that the plants were pulled out for weight measurements, all the lateral branches in the latter variety had acquired a vigorous vegetative growth that surpassed Queen's and Valiant's. The standard error and least differences required for significance between mean fresh weights of the whole tomato plants are shown in the following tabulation:

\section{Ilem}

Least significant difference between highest and lowest means

Least significant difference between highest and 2nd lowest

Least significant difference between 2 adjacents Standard error 60.54 with 12 d.f.

$\begin{array}{cc}\text { 5-percent level } & \text { I-percent level } \\ 254.14 & 332.81 \\ 228.12 & 304.97 \\ 186.37 & 261.40\end{array}$

\section{Dry Weight of Whole Plant}

Table 4 also shows the results for the dry weight of whole tomato plants. The mean total dry weight in grams for the whole tomato plants was 127.31, 107.96, 89.61, and 75.30 for Rutgers, Earliana, Valiant, and Queens, re- 
spectively. Only Rutgers weighed significantly more than Queens. Comparisons among the other varieties did not show any significant difference. The standard error and least differences required for significance between mean dry weights of whole tomato plants are shown in the following tabulation:

$$
\text { Ilem }
$$

Least significant difference between highest and lowest means

Least significant difference between highest and 2nd lowest

Least significant difference between 2 adjacents Standard error 10.44 with 12 d.f.

$$
\text { 5-percent level 1-percent level }
$$

57.42

39.36

52.62

32.16

45.10

The results on the tomato fresh and dry weights suggest that the fresh and dry weights of the leaves are better indices of earliness than the fresh and dry weights of the whole plants.

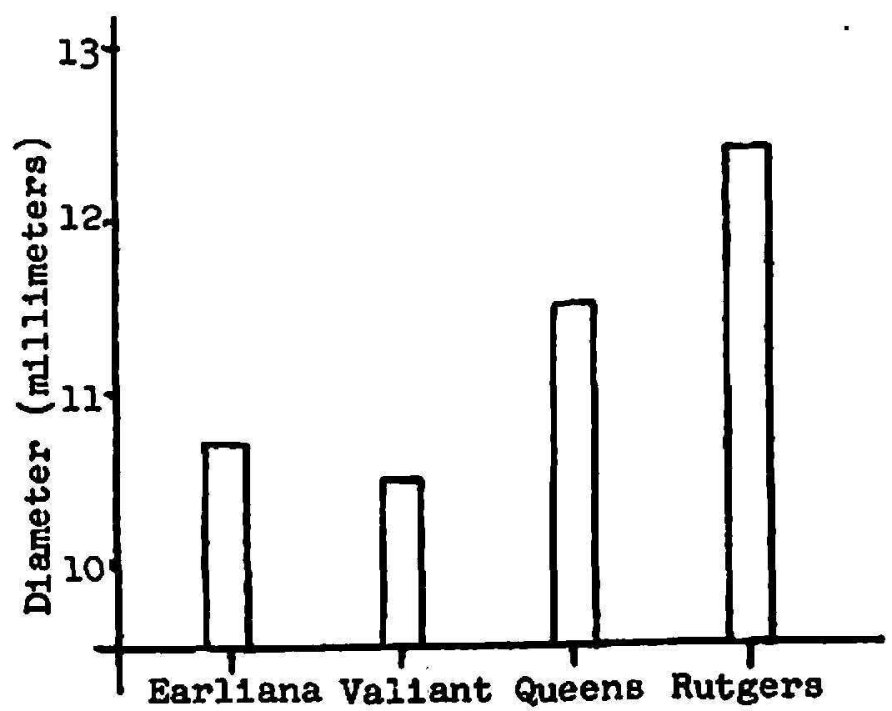

Fra. 6.-Main stem diameter 2 leaves below position of the first inflorescence of the main stems of 4 tomato varieties.

MAIN-STEM DIAMETER TWO LEAVES HELOW THE FIRST FLOWER CLUSTER

The mean main-stem diameters, in millimeters, of the four tomato varieties were 13.41, 12.50, 11.69, and 11.49, for Rutgers, Queens, Earliana, and Valiant, respectively (see fig. 6). In Rutgers the stem diameter was highly significantly thicker than in the other three varieties. Queen variety had highly significantly thicker stem diameter than Earliana and Valiant. This may be because late varieties take a longer time in vegetative growth before fruiting than the earlier ones, producing in such way the difference in stem diameter. The difference between Valiant and Earliana was not significant. This result suggests that an early variety has a thinner stem 
than a late one. The standard error and least differences required for significance between mean stem diameters are presented in the following tabulation:

Item

Least significant difference between highest and lowest means

Least significant difference between highest and 2nd lowest

Least significant difference between 2 adjacents

Standard error 0.11 with 12 d.f. 5-percent level

0.46

.41

.34
I-percent leoel

0.61

\section{YIELDS}

The yield was measured in terms of number and weight of harvested fruits (see table 5); Earliana produced a significantly larger number of

TABLE 5.-Mean total number and weight of fruits produced on the 4 tomato varieties studied

\begin{tabular}{l|c|c|c|c}
\hline \multirow{2}{*}{ Character measured } & \multicolumn{4}{|c}{ Results for variety indicated } \\
\cline { 2 - 3 } & Earliana & Valiant & Queens & Rutgers \\
\hline Number of fruits & 53.40 & 35.40 & 40.20 & 32.60 \\
Fruit weight (pounds) & 10.15 & 6.56 & 6.61 & 7.44 \\
\hline
\end{tabular}

fruits than Rutgers and Valiant. No significant differences were found bctween Queens, Valiant, and Rutgers. There is no explanation for the high yield in Earliana over Rutgers, aside from the fact that Rutgers was harvested only four times, whereas the earlier varieties were harvested six. On Rutgers the yield data were discontinued after the fourth picking because of the high incidence of diseases and nematodes.

No significant differences were found between varieties for the mean total weights of fruit harvested presented in table 5 .

The standard error and least differences required for significance between mean total numbers of fruits harvested are presented in the following tabulation:

Ilem

Least significant difference between highest and lowest means

Least significant difference between highest and 2nd lowest

Least significant difference between 2 adjacents

Standard error 4.33 with 12 d.f.

\section{5-percent level $\quad 1$-percent level}

18.19

23.82

16.32

21.82

13.34

18.70 


\section{SUMMARY}

An experiment was conducted to determine the association of certain characters with earliness in the tomato, at the Isabela Agricultural Experiment Substation. Four varieties were included in this study, namely: Earliana, first early; Valiant, second early; Queens, midseason; and Rutgers, late. The information recorded was as follows: 1, Leaf production at weekly intervals; 2 , node number at which the first consecutive four-flower clusters appeared on the main stem; 3 , percentage of the first four flowering lateral branches originating four leaves below or above the position of the first flower cluster on the main stem; 4, fresh and dry weights of five mature tomato leaves per plant collected from the first and the last plant in each replication; 5 , fresh and dry weights of each whole tomato plant that was planted at the beginning and at the end of each replicate; 6 , stem diameter two leaves below the first inflorescence; and 7, yield measured in terms of total number and weight of fruits produced.

The results of this experiment strongly indicate that earliness is associated with the following characters:

1. High rate of leaf production, i.e., an early variety producing more leaves per unit of time than a late one.

2. Small number of leaves from the cotyledons to the position of the first inflorescence on the main stem.

3. A relatively large number of leaves from the first to the second, and from the second to the third inflorescences on the main stem.

4. Concentration of the first four flowering branches within a relatively small zone on the main stem, a few leaves below or above the position of the first inflorescence.

5. Relatively thin stem.

6. Relatively small leaves.

\section{RESUMEN}

Este experimento se llevó a cabo en la Subestación Experimental Agrícola de Isabela con el propósito de asociar la precocidad con ciertos caracteres de la planta de tomate. Las variedades usadas para este estudio fueron: Earliana, primera temprana; Valiant, segunda temprana; Queens, intermedia; y Rutgers, tardía. Se tomaron datos de estas variedades en cuanto a los siguientes caracteres: 1, Cantidad de hojas producidas a intervalos de una semana; 2 , posición en que aparecen la primera, segunda, tercera y cuarta inflorescencias en el tallo principal; 3 , porcentaje de las primeras cuatro ramas laterales florecidas que apareció cuatro hojas más abajo o sobre la primera inflorescencia en el tallo principal; 4, pesos húmedo y seco de cinco hojas tomadas de la primera y de la última planta de cada 
repetición; 5, pesos húmedo y seco de la planta entera usando la primera y la última planta de cada repetición; 6 , diámetro del tallo tomado dos hojas más abajo de la primera inflorescencia; y 7 , número y peso total de frutas cosechadas.

Los resultados estadísticamente significativos demostraron que la precocidad en el tomate está asociada a los siguientes caracteres:

1. Alto número de hojas producidas por unidad de tiempo transcurrido.

2. Un número reducido de hojas comenzando desde las hojas cotiledonarias hasta la posición en que aparece la primera inflorescencia.

3. Alto número de hojas entre la primera y segunda y la segunda y tercera inflorescencia producidas en el tallo principal.

4. Concentración de las cuatro primeras ramas laterales florecidas dentro de una zona reducida que incluye cuatro hojas hacia abajo o sobre la posición en que aparece la primer inflorescencia en el tallo principal.

5. Tallo relativamente delgado.

6. Hojas relativamente pequeñas.

\section{LITERATURE CITED}

1. Rick, Charles M., and Butler, L., Citogenetics of the tomato, Advances in Genetics, 8 267-382, 1956.

2. Yeager, A. F., Determinate growth in the tomato, J. Hered. 18 263-5, 1927. 